\title{
A spatial analysis of plant phenophase changes and the impact of increases in urban land use
}

\author{
Alexis Comber ${ }^{\mathrm{a} *}$ and Chris Brunsdon ${ }^{\mathrm{b}}$ \\ ${ }^{a}$ Department of Geography, University of Leicester, UK \\ ${ }^{\mathrm{b}}$ National Centre for Geocomputation, NUI Maynooth, Maynooth, Ireland
}

\begin{abstract}
Changes in phenology are indicators of climate change. Urban land use influences local climates through mechanisms such as urban heat island (UHI) effects. This research examined the spatio-temporal variations in first flowering with changes in urban land use in England and Wales. It used standard ordinary least squares (OLSs) regressions and geographically weighted regressions (GWRs) to analyse changes in phenophase observation date between 1934 and 2007 for three tree species. The OLS models suggested that first flowering was getting earlier: blackthorn by 0.28 days per year, hawthorn by 0.16 days per year and horse chestnut by 0.13 days per year. These rates were found to vary spatially when GWR was used and the greatest rates of change were found to be highly localized. The addition of land use change was found to improve the model fit and suggested that a $10 \%$ increase in urban land use was also associated with phenophase advancement of 1.20 days for blackthorn, 0.57 days for hawthorn and 0.90 days for horse chestnut. When the impacts of urban land use changes was analysed using GWR, the associations with phenophase advancement were found to vary spatially, strongest associations were generally more pronounced in the north and especially in the extreme south-west and the north for all species. The results of this research suggest that the impacts of climate changes and the effects of urban land use changes on phenology vary spatially and that the impacts of urban expansion, such as UHI effects, may not be uniform. These findings suggest the need for spatially explicit analyses to quantify the local impacts and drivers of climate changes and their associated feedbacks.
\end{abstract}

KEY WORDS phenology; land use change; climate change; geographically weighted model

Received 2 April 2013; Revised 29 March 2014; Accepted 7 April 2014

\section{Introduction}

Land use has been identified as a driver of regional climates in many studies (Shepherd and Burian, 2003; Ashley et al., 2012; Hoffmann et al., 2012) and reviews (Shepherd, 2005; Pitman et al., 2012). The expansion of urban land use in particular has been found to affect local temperature, rainfall, convection, storms, boundary layer interactions and Pitman et al. (2012, p. 329) noted that 'there are literally hundreds of scientific papers that highlight the impact of urban surfaces' on local climates. The main impacts have been found to relate to changes in surface albedo, with associated impacts on evapotranspiration rates, and turbulence reductions in the planetary boundary layer.

Some research has considered the impacts on energy dynamics of high concentrations of urban land use. These have been found to modify local climate (Foley et al., 2005) through the 'urban heat island' (UHI) effect (Landsberg, 1981). Temperature and energy gradients between urban and rural areas occur because of large amounts of heat being stored in the urban fabric and then being released as the external air temperature cools, e.g. after sunset. Temperature gradients of up to $7^{\circ} \mathrm{C}$ between urban

\footnotetext{
* Correspondence to: A. Comber, Department of Geography, University of Leicester, LE1 7RH, UK. E-mail: ajc36@le.ac.uk
}

and rural areas have been found in the UK (Wilby, 2003). These arise as radiation is reflected or absorbed by buildings and higher levels of air pollution in urban areas (Smith and Levermore, 2008). These are accentuated at night due to the suppression of long-wave radiation emissions and the release of stored urban heat (Oke, 1987). As a result, net energy and heat losses in the city are lower than in the surrounding rural matrix. The increasing impacts of UHIs on local climate patterns are expected continue as urbanization and urban land use increases (United Nations, 2005).

Land cover and land use are important components of climate models. Changes in land cover/land use have been identified as powerful drivers of regional climate changes (Feddema et al., 2005) and much recent research has identified the importance of understanding how local feedbacks arising from land use change affect the local climate. For example, Strengers et al. (2010) found the impacts of land cover/land use change on temperature to be more important than any additional warming due to natural vegetation dynamics. Critically, they noted that these effects were stronger at regional scales than at global ones. In an editorial of a special issue of the International Journal of Climatology, Dirmeyer et al. (2010, p. 1906) commented 'that there can be significant local effects to observed changes in land use' and the 'impacts from land use change have their strongest signatures at small scales'. 
Additionally, there has been an increasing recognition of the need to understand how these interactions and impacts vary spatially (Soares-Filho et al., 2006; Malhi et al., 2008; Cochrane and Barber, 2009; Poulter et al., 2010).

Changes in phenology, the timing of recurring natural phenomena, have long been studied as a proxy for climate changes (Walther et al., 2002). In particular, plant phenology has been shown to provide a reliable indicator of the local environment (Walther, 2003). This is because plant development is driven by a range of environmental and climate factors. Consequently, changes in plant phenology are indicative of climate changes (Walther et al., 2002). For example, the timings of early development events in trees are driven by temperature and photoperiod (Korner and Basler, 2010). Although the end to dormancy in trees is a response to a finely tuned interplay between the species' chilling requirement, photoperiod and accumulated temperature, temperature is considered to be the dominant factor in spring phenology including first flowering (Chuine et al., 2010). Changes in phenophase (phenology timings) are therefore recognized to be driven by changes in climate, especially temperature (Visser and Both, 2005; Peñuelas and Filella, 2009), and there is a vast literature on this topic. For example, Chmielewski and Rötzer (2001) showed that early spring warming of $1{ }^{\circ} \mathrm{C}$ was associated with an advance in the beginning of growing season of 7 days. Other work has noted the impacts of winter warming on dormancy. Yu et al. (2010) not only identified an advancement of the growing season, but also commented on the effect of warm winters in delaying early plant development due to a slower fulfilment of the chilling requirements needed to break dormancy. Similar push-pull effects have also been noted by Pope et al. (2013) who found that plant development as a response to warmer temperatures could be delayed due to a lack of adequate chilling. Although the impact of urban surfaces on climate is well recognized (Bornstein, 1968), mixed results have been found in research that has considered the impacts of UHIs on phenology, perhaps partly due to the scale, temporal resolution and method of observations. Using both large- and small-scale observations, Roetzer et al. (2000) examined the impacts on plant and tree phenology of urban areas and found that rural areas were more closely associated with earlier flowering than urban areas. In contrast, Zhang et al. (2004) analysed coarse resolution remote sensing data to explore urban-rural differences in plant phenology for large urban areas $\left(>10 \mathrm{~km}^{2}\right)$. They showed that the effect of urban climate on phenology decays exponentially with distance but still exerts a substantial influence on phenology up to $10 \mathrm{~km}$ beyond urban area. Jochner et al. (2013) examined the effects of UHIs on tree phenology and found that the impact of urban land use varied in different climate zones (tropic and temperate). In another study, Jochner et al. (2012) showed that the mean trend for the nine phenological events was towards earlier phenophase, with the impact of urban land use found to be variable.
In summary, changes in land use affect local climates and areas of urban land use are associated with higher local temperatures than rural areas. In climate change research, the need to understand the varying impacts of local land use changes on regional climates has been identified. Plant phenological timings are a well-established and reliable proxy for climate factors and can be used to examine changes in local climate, especially temperature.

This study analysed historical land use change using data from the 1930s and 2007 against volunteer observations of the timing of tree phenology events for the same period. The study sought to examine how phenophase (in this case first flowering) had changed over time to examine the impacts of changes in urban land use and in both cases to examine how these relationships varied spatially.

\section{Methods}

\subsection{Data}

The Land Utilization Survey of Britain was started in the 1930s (Stamp, 1934). In the recently released digitized version, the original 15 classes were collapsed into eight land use classes that included an 'urban and suburban' class composed of urban areas, suburban gardens and roads. The Land Cover Map 2007 (Morton et al., 2011) is a classification of land cover and land use derived from medium resolution satellite imagery. It is available at a range of thematic and spatial scales including $1 \mathrm{~km}$ summaries that describe the proportion of ten classes, including 'built-up areas and gardens'. A spatial overlay was used to summarize the amount of urban land use reported in each survey over Ordnance Survey's 10-km grid squares. Each square reported the proportions of land use classified as urban and suburban in the 1930s and as built-up areas and gardens in 2007.

Data describing the timing (Julian Day) and locations (Easting and Northing) of observations of tree phenology events were provided by the Woodland Trust (http://www.woodlandtrust.org.uk). These data were originally collected by a diverse range of groups and citizens with an interest in the natural environment, an activity which has a long history in the UK, with some of the data records going back over 100s of years. The Woodland Trust undertakes a number of activities to curate and collate these data for a number of species (e.g. tree, bird, amphibian and insect). This research analysed data of the timing of first flowering for three tree species: hawthorn (Crataegus monogyna), blackthorn (Prunus spinosa) and horse chestnut (Aesculus hippocastanum) between 1934 and 2007.

Tree phenology events were analysed because they are less likely to be affected by factors other than local climate. For example, many observers record the last and first sight of swallows (Hirundo rustica). However, because of their mobility and migratory habits, it would be difficult to know whether any observed trends in phenology were associated with local conditions (such as land use change) or with changes in conditions elsewhere, e.g. due to warmer 
temperatures in Africa. In contrast to bird, amphibian, insect and other animal phenology which have the ability to 'escape' rapidly from any changes, local environments, plants, especially trees, can only do this slowly.

The land use and phenology data were brought together and augmented in the following way. For each observation, elevation was determined using the Google Elevation API which has a resolution of 3 arc-seconds $(\sim 90 \mathrm{~m})$. The amount of urban land use change between 1934 and 2007 was attached to each observation from the Ordnance Survey grid square in which the observation occurred, proportionate to the number of years that had passed since 1934 This weighted value of land use change, $\Delta \mathrm{LU}$, was calculated for each observation as follows:

$$
\Delta \mathrm{LU}=\left(1-\frac{(2007-\text { Year })}{(2007-1934)} \times\left(\mathrm{LU}_{2007}-\mathrm{LU}_{1934}\right)\right)
$$

where Year is the year of the observation, $\mathrm{LU}_{2007}$ the proportion of urban land use in 2007 and $\mathrm{LU}_{1934}$ is the proportion of urban land use in 1934. In this way, the urban land use change at each location was scaled relative to the amount of time between 1934 and the year of the observation. Finally, the end of year dates after Julian Day 304 was converted to negative number, although this affected only one blackthorn observation and this record was allocated to the following calendar year. Thus, the record for each observation included the following data attributes that were used in the analysis: day of observation (phenophase), year of observation, proportion of urban land use change and location of observation.

The temporal and spatial distributions of the first flowering data for the three tree species are summarized in Figure 1. They exhibit notable differences in timing and in their geographical ranges. Each dataset shows two intense periods of observation from the 1930s to the mid-1940s and then from the late 1990s. The number of observations for each species falling within the area covered by the land use data for England and Wales were 13786 for blackthorn, 45970 hawthorn and 11720 for horse chestnut.

\subsection{Analysis}

The sequence of analyses was as follows. First, changes in phenophase over time were explored. Then, a second set of analyses considered the relationship between urban land use changes and phenophase changes. In each case, a standard regression approach was initially applied, followed by a geographically weighted regression (GWR) analysis (Brunsdon et al., 1996) in order to explore the spatial variation in the observed relationships. GWR is similar to an ordinary regression, but the regression coefficients are allowed to vary over space. In this case, they were computed over a grid of locations spaced at $10 \mathrm{~km}$, as shown in Figure 1. At each location, a local regression model was estimated using the data points under a kernel, and the contribution of each data point was weighted by its distance to the centre of the kernel. The kernel was specified to include the nearest $5 \%$ of the data points to the location being considered. The individual flowering events were analysed in turn.
For each analysis, the Julian Day, Day, was converted to an elevation corrected index of phenophase as follows. First, regression coefficients for elevation were estimated:

$$
\text { Day }=\beta+\beta_{1} \text { Year }+\beta_{2} \text { Elev }
$$

where Year was the year of the observation and Elev was the elevation of the observation above sea level.

Next, the coefficient for elevation from Equation (2), $\beta_{2}$ Elev, was subtracted from Day to determine a new indicator, Day.ec, where the variation due to elevation is eliminated:

$$
\text { Day.ec }=\text { Phen }-\left(\beta_{2} \times \text { Elev }\right)
$$

The objective here was to 'flatten out' any changes due to elevation in the timing of first flowering, as suggested by Jochner et al. (2012) especially for urban areas, rather than to examine the impact of elevation itself. Therefore, an elevation corrected index of day as a fixed coefficient for height was used, rather than a geographically varying one in the GWR analyses below.

Four analyses were then undertaken:

(i) A standard regression to estimate the changes in phenophase regressing Day.ec with Year,

(ii) A GWR analysis to examine spatial variation in phenophase changes over time,

(iii) A regression to estimate the changes in phenophase over time and with urban land use change, regressing Day.ec against Year and $\Delta \mathrm{LU}$ and

(iv) A GWR analysis to determine the spatial variation in the association between changes in Day.ec with Year and $\Delta \mathrm{LU}$.

These are formally described in turn below.

To model changes in phenophase over time, the elevation corrected index of first flowing date, Phen.ec, was regressed against the year of observation, Year:

$$
\text { Phen.ec }=\beta_{0}+\beta_{1} \text { Year }
$$

A geographically weighted model, extending Equation (3), was then specified as follows:

$$
\text { Phen.ec }=\beta_{0_{\left(u_{i}, v_{i}\right)}}+\beta_{1} \operatorname{Year}_{\left(u_{i}, v_{i}\right)}
$$

where $\left(u_{i}, v_{i}\right)$ is a vector of two-dimensional co-ordinates describing the location of $i$ over which the coefficient estimates are assumed to vary.

The impacts of urban land use changes, $\Delta \mathrm{LU}$, on phenophase change were modelled using a linear regression:

$$
\text { Phen.ec }=\beta_{0}+\beta_{1} \text { Year }+\beta_{2} \Delta \mathrm{LU}
$$

Finally, this was extended to a geographically weighted model to compute local regression coefficients:

$$
\text { Phen.ec }=\beta_{0_{\left(u_{i}, v_{i}\right)}}+\beta_{1} \operatorname{Year}_{\left(u_{i}, v_{i}\right)}+\beta_{2} \Delta \mathrm{LU}_{\left(u_{i}, v_{i}\right)}
$$

All of the statistical analysis and mapping were implemented in $\mathrm{R}$ version 3.0.2, the open source statistical software (http://cran.r-project.org), using the spgwr and 

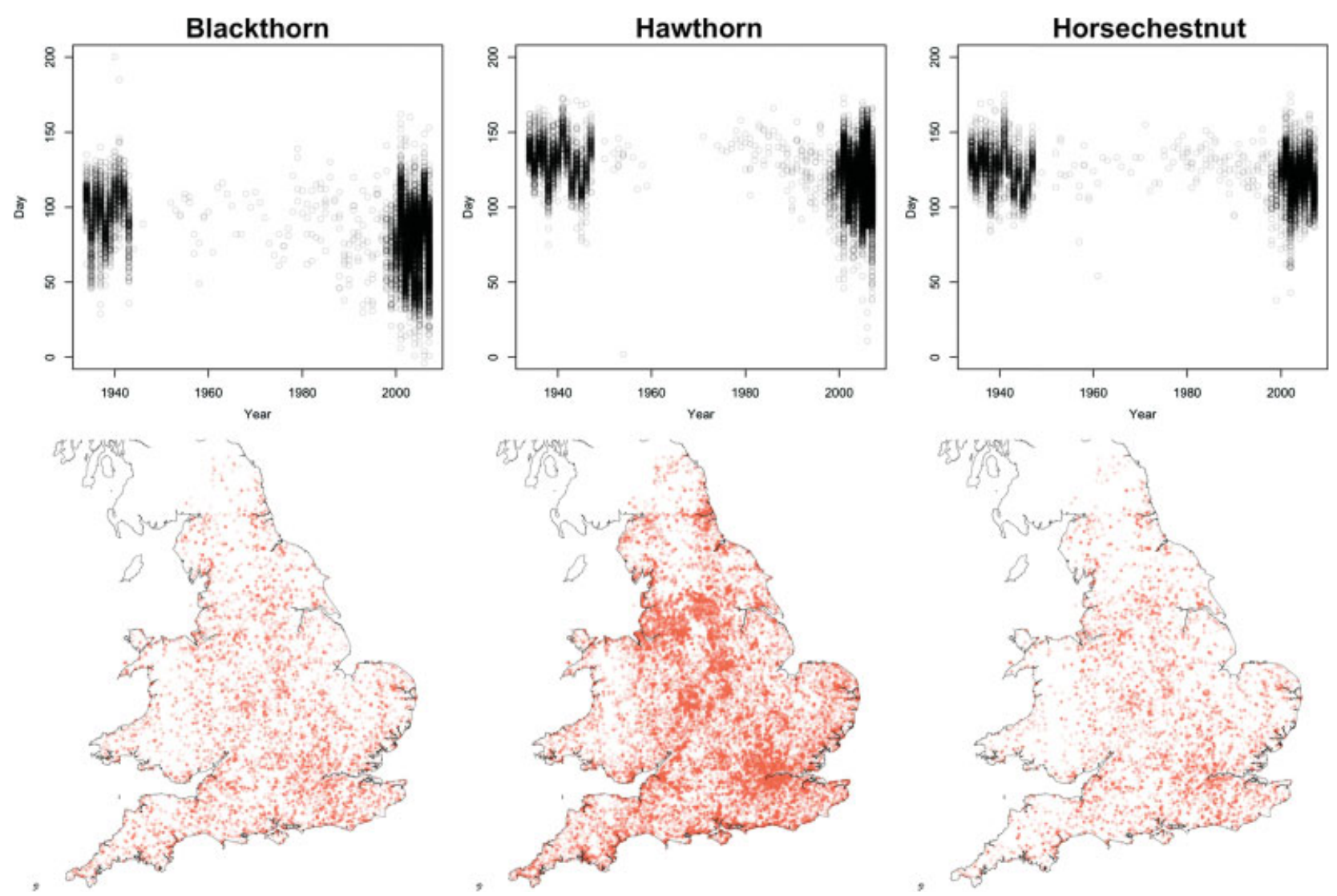

Figure 1. The spatial and temporal distributions of blackthorn $(n=13786)$, hawthorn $(n=45970)$ and horse chestnut $(n=11720)$ first flowering events in the UK between 1934 and 2007.

GISTools libraries. The code used in this analysis will be provided to interested researchers on request.

\section{Results}

\subsection{Urban land use change}

Figure 2 shows the changes in urban land use between the 1930s and 2007. The symbols are linearly proportional to the changes in each $10-\mathrm{km}$ grid square and the map highlights the increases in urban land use in large population centres as would be expected. In rural areas, some increases are also evident as well as some decreases. The decreases, although very small, are counter-intuitive and are perhaps indicative of differences between the two survey methodologies and classifications. Further investigation of the negative urban land use changes shows that they are likely to be noisy (the 25th percentile is 0.000 , the median is 0.011 and the 75th percentile is 0.049) rather than indicative of actual declines in urban extent.

\subsection{Changes in phenophase}

The results of regressing phenophase against the year of observation (Equation (4)) are shown in Table 1. This shows that phenophase for each species is getting earlier at rates of between 0.28 and 0.13 days per year - equating to 21 and 9 days, respectively, over the period considered - and that first flowering in blackthorn is getting earlier at a faster rate than the other species.

GWRs (Equation (5)) were used to examine the spatial variations in the relationship of the rate of phenophase change. Table 2 summarizes the variation in the coefficient estimates modelled by the GWR analyses. The mean values are similar to those of the ordinary regression described above, with small differences arising form the kernel-based approach. The distributions indicate that the rates of phenophase change vary for a large number of locations: from -0.31 (blackthorn) to -0.11 (horse chestnut) days per year. The interquartile ranges (IQRs) suggest that there is less variation in the geographically weighted models for hawthorn than for blackthorn and horse chestnut.

The spatial distribution of the coefficient estimates from the GWR models is shown in Figure 3. These suggest some consistent patterns and local variations in coefficient estimates, with generally faster rates of phenophase change between 1934 and 2007 (lighter shades) to the north of the study area for hawthorn and horse chestnut and in the central region for blackthorn. Outside of these areas, there are some distinct regions with low rates of phenophase change. Blackthorn has much slower rates of phenophase change in the west and south-west, hawthorn in the south-east around London and horse chestnut in the area to the south-west of Birmingham (NB Figure 2 includes the locations of the areas referred to). Higher rates of phenophase change can 


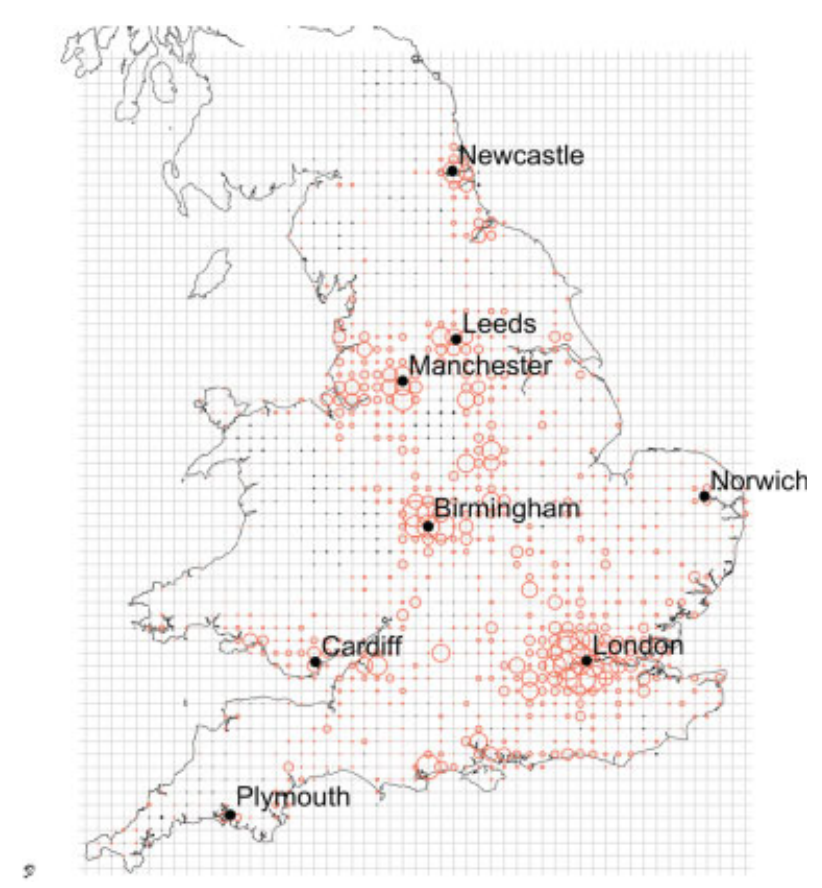

Figure 2. Changes in urban land use from the 1930s to 2007 summarized over a 10-km grid. Increases are shown in red and decreases are in black, with the size of the plot character indicating the magnitude of change. Some of the major urban centres are indicated.

be seen in the north for all species, although this is more of a centrally located trend for Blackthorn.

\subsection{The impact of urban land use changes}

The next stage in the analysis was to consider relationship, if any, between changes in urban land use and changes in phenophase. A land use change term was added to linear regressions (Equation (6)) and the geographically weighted models (Equation (7)). The results of the linear regression are summarized in Table 3 . These indicate similar coefficient estimates for the year of observation to those in Table 2 and that the proportion of land use change is also significantly associated with phenophase. Specifically, each $10 \%$ increase in urban land use is associated with 1.19 days of advancement in phenophase for blackthorn, 0.56 days for hawthorn and 0.90 days for horse chestnut.

The models produced by Equations (4) and (6), with and without land use, were compared using an analysis of variance. This determines whether there is significant evidence to reject a null hypothesis of there being no influence on phenophase associated with urban land use change. The results in Table 4 indicate that, for each species, the null hypothesis can be rejected and that the addition of urban land use change significantly improves the model fit in each case.

Finally, the linear regressions were extended to geographically weighted models (Equation (7)) to explore spatial variations in the impact of urban land use on phenophase. The distribution of the land use change coefficients associated with phenophase are summarized in Table 5. These show similar trends of mean values to those given in Table 3 but with considerable spatial variation for all species as indicated by the IQR of the coefficient estimates, and much greater variation for blackthorn than for hawthorn or horse chestnut. The maps of geographically weighted model coefficients are shown in Figure 4. These show that the highest coefficients for blackthorn are in the north and east of the study area (more than 1.9 days of advancement in phenophase per $10 \%$ of urban land use increase) and the lowest to the central south-east (less than 0.77 days per $10 \%$ of urban land use increase). For hawthorn and blackthorn, the lowest coefficients are in the central western areas (less than 0.35 and 0.65 days per $10 \%$ increase in land use, respectively) and the highest are found in the eastern and western extremes as well as in areas in the north.

\subsection{Summary of results}

It is possible to make a number of summary statements relating to changes in phenophase, and how first flowering phenophase is related to changes in urban land use:

(1) Phenophase is getting significantly earlier (advancing) for the three tree species considered over the period 1934-2007 (Table 1);

(2) When the influence of location was considered, the rates of phenophase advancement were found to vary

Table 1. The coefficient estimates describing the rate of change in phenophase (days per year) for blackthorn, hawthorn and horse chestnut between 1934 and 2007.

\begin{tabular}{lccccrr}
\hline Species & Estimate & CI 2.5\% & CI 97.5\% & Standard error & $t$ value & $\operatorname{Pr}(>|t|)$ \\
\hline Blackthorn & -0.284 & -0.297 & -0.271 & 0.006 & -43.881 & 0.000 \\
Hawthorn & -0.160 & -0.167 & -0.152 & 0.004 & -42.143 & 0.000 \\
Horse chestnut & -0.127 & -0.135 & -0.120 & 0.004 & -33.197 & 0.000 \\
\hline
\end{tabular}

Table 2. The variations of the coefficients for changes in phenophase (days per year) as estimated using GWR.

\begin{tabular}{lccccc}
\hline Species & First quartile & Median & Mean & Third quartile & IQR \\
\hline Blackthorn & -0.312 & -0.291 & -0.287 & -0.270 & 0.042 \\
Hawthorn & -0.179 & -0.163 & -0.167 & -0.154 & 0.024 \\
Horse chestnut & -0.155 & -0.129 & -0.135 & -0.114 & 0.041 \\
\hline
\end{tabular}



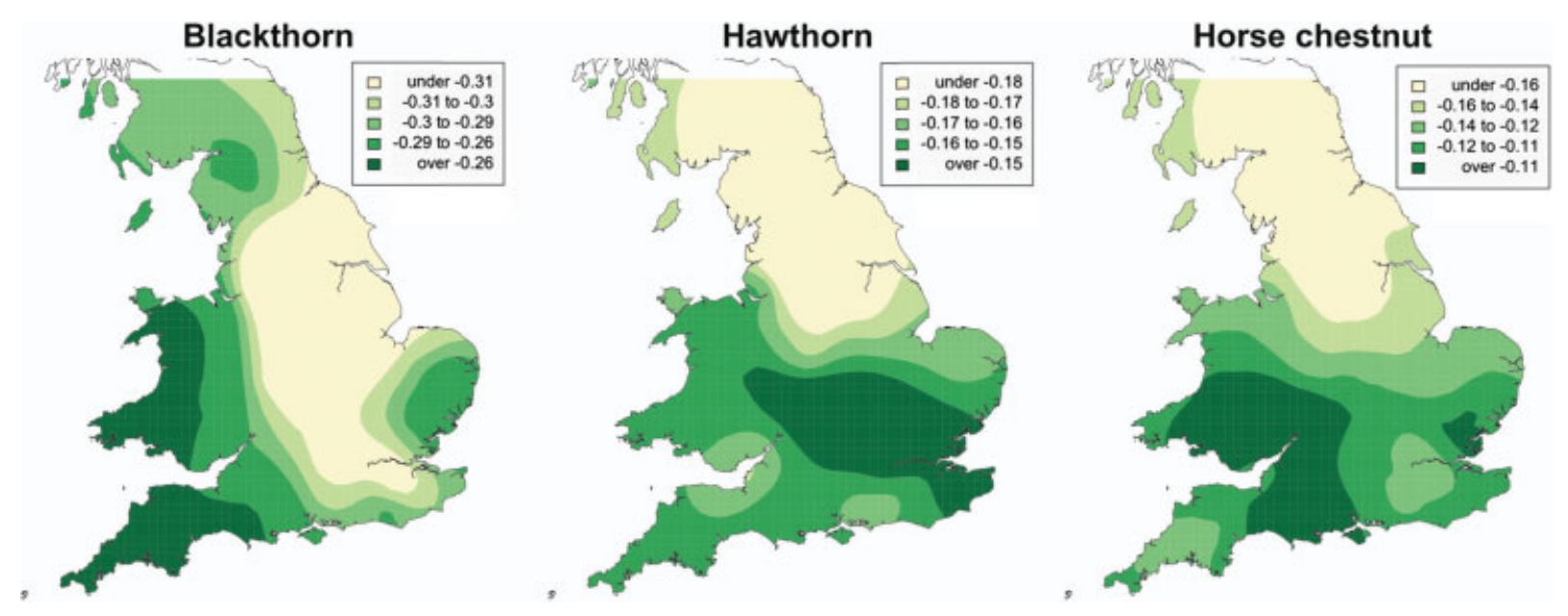

Figure 3. Spatial variation in the changes in phenophase (days per year) for blackthorn, hawthorn and horse chestnut as estimated using GWR.

Table 3. The coefficient estimates describing the relationship between urban land use change and year of observation with phenophase for blackthorn, hawthorn and horse chestnut between 1934 and 2007.

\begin{tabular}{lcccc}
\hline Species and factor & Estimate & Standard error & $t$-value & $\operatorname{Pr}(>|t|)$ \\
\hline Blackthorn and year & -0.269 & 0.007 & -39.844 & 0.000 \\
Blackthorn and LUC & -11.984 & 1.493 & -8.029 & 0.000 \\
Hawthorn and year & -0.150 & 0.004 & -38.667 & 0.000 \\
Hawthorn and LUC & -5.721 & 0.469 & -12.198 & 0.000 \\
Horse chestnut and year & -0.113 & 0.004 & -27.677 & 0.000 \\
Horse chestnut and LUC & -9.041 & 0.894 & -10.114 & 0.000 \\
\hline
\end{tabular}

spatially (Table 2), with some locations experiencing much higher and lower rates of change than others (Figure 3);

(3) Urban land use change is a significant predictor of phenophase (Table 3) and was found to improve the models (Table 4) and

(4) The relationship between phenophase and urban land use change varies spatially (Table 5). It is generally more pronounced in the north and in the extreme south-west for all species, and generally less in central areas. There is considerable spatial variation in the effect of urban land use change within and between species (Figure 4).

\section{Discussion}

The underpinning rationale for this research derives from three areas of consideration. First, early post-dormancy development events such as flowering in plants are mainly driven by temperature. Therefore, any changes in early year temperatures would affect phenophase, especially for development events that occur towards the start of the growing season. Second, land use changes are known to result in local and regional climate changes. Specifically, urban land uses typically result in higher urban temperatures than are found in the surrounding rural matrix as energy and heat are retained within urban structures. Finally, in geographical analyses, the expectation is that relationships between variables, such as phenophase, year of observation and land use change, will vary over geographic space. They are not assumed to be stationary or to be location independent. Rather, one of the fundamental principles of spatial analysis or geocomputation is to test for non-stationarity and the existence of spatial variability of statistical models. Hence, the use of geographically weighted approaches - in this case GWR as proposed by

Table 4. A comparison of regression models of phenophase against year of observation (Year) with and without land use change $(\Delta \mathrm{LU})$.

\begin{tabular}{lcccccc}
\hline Model & Res.Df & RSS & Df & Sum of square & $F$-value & $\operatorname{Pr}(>F)$ \\
\hline Blackthorn with Year & 13784 & 4758181.9 & - & - & - & - \\
Blackthorn with Year and $\Delta$ LU & 13783 & 4736031.4 & 1 & 22150.5 & 64.5 & 0.000 \\
Hawthorn with Year & 45968 & 7955008.4 & - & - & - & 0.000 \\
Hawthorn with Year and $\Delta$ LU & 45967 & 7929342.6 & 1 & 25665.8 & 148.8 & - \\
Horse chestnut with Year & 11718 & 1480139.8 & - & - & 12809.7 & 102.3 \\
Horse chestnut with Year and $\Delta$ LU & 11717 & 1467330.1 & 1 & 0.000 \\
\hline
\end{tabular}


Table 5. The variations in urban land use change coefficient estimates associated with phenophase arising from the GWR models.

\begin{tabular}{|c|c|c|c|c|c|}
\hline Species & First quartile & Median & Mean & Third quartile & IQR \\
\hline Blackthorn LUC & -17.650 & -13.280 & -13.280 & -8.372 & 9.278 \\
\hline Hawthorn LUC & -7.808 & -6.178 & -5.778 & -3.817 & 3.991 \\
\hline Horse chestnut LUC & -10.680 & -8.991 & -8.783 & -6.832 & 3.848 \\
\hline
\end{tabular}
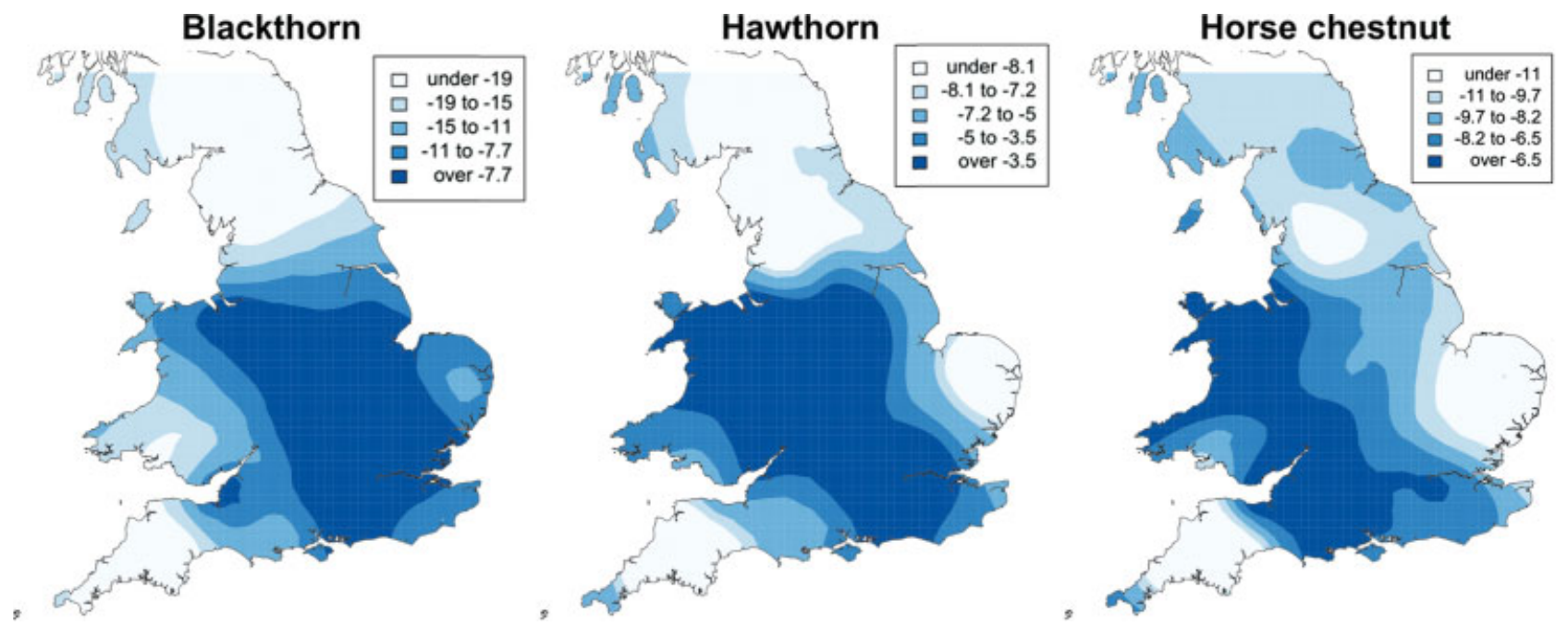

Figure 4. Spatial variation in coefficients of urban land use change as a predictor of the phenophase of first flowering for blackthorn, hawthorn and horse chestnut as estimated using GWR.

Brunsdon et al. (1996) - is to develop location-specific statistical models in this research.

In order to the address these considerations, this study analysed volunteer observations of first flowering date in England and Wales for three species hawthorn $(C$. monogyna), blackthorn ( $P$. spinosa) and horse chestnut $(A$. hippocastanum) over time and against land use changes. This research has found that first flowering phenophase has become earlier over the period 1934-2007, with rates of change found to be greatest for blackthorn $(-0.28$ days per year) and lowest for horse chestnut $(-0.13$ days per year). These rates are similar to those found in other studies (Menzel et al., 2006). When spatially explicit regressions were applied to the data, spatial variations in the rates of phenophase change were observed in the model outputs, with broadly north-south gradients (faster rates to the north) in the rates of change for hawthorn and horse chestnut and with some east-west effect for all species. That is, the rates of phenophase change were not found to be even across the study area within and between species.

The addition of urban land use change to the models estimating phenophase significantly improved and the null hypotheses of there being no influence on phenophase associated with urban land use change were rejected. Urban land use change was found to be significantly associated with phenophase with each $10 \%$ increase in urban area predicting phenophase advancement of 1.19 days for blackthorn, 0.56 days for hawthorn and 0.90 days for horse chestnut. The spatial variations in these relationships as determined using geographically weighted models showed clear differences within and between the species considered.

The spatial variations in the results could be due to a number of different factors influencing the patterns of climate change and or urban land use changes, but without further analysis it is difficult to unpick them. For example, increases in urban land use changes typically reflect some form of building or development, that is, from undeveloped to developed in some way (e.g. from fields to houses, etc.). It might be expected that increases in urban extent in population and in built-up areas will produce and trap heat, thereby increasing local ambient temperatures, creating more stable heat islands and, in so doing, drive early plant development. However, the patterns in Figure 4 do not solely reflect urban development and suggest that the effect of land use changes are more pronounced in some areas that have experienced urbanization than in others, indicating the possible effects of other factors - an example of Simpson's Paradox (Simpson, 1951; Appleton et al., 1996) of the problems of ignoring an explanatory covariate that is correlated to an outcome variable. One possible factor for the observed variations could be associated with the pull effect of warmer winter temperatures on dormancy mitigating against the push effect of earlier phenophase.

Spatial variations in phenophase have been observed in other studies (Schleip et al., 2009; Askeyev et al., 2010) and modelling the spatial variations in statistical relationships between variables has a number of advantages. Principally, they allow the impacts of possible driving processes to be evaluated at local scales as suggested by a number of researchers (Walther et al., 2002; Stöckli et al., 
2011). The links between land use and phenology have also been identified by many researchers and recent research in this topic has indicated the need to examine the impact of local land changes on local climate (Dirmeyer et al., 2010; Pitman et al., 2012). However, despite the existence of many methods arising from spatial information sciences for examining local variations, there are few examples of their use in such analyses. This research has highlighted one possible method for doing that.

There are a number of methodological considerations associated with this research.

First, the land use change data was derived from the proportions of urban land use in 10-km grid cells at two time intervals. The 1930s and 2007 data were measured and captured in different ways through volunteer field survey and statistical analysis of medium resolution remote sensing data, respectively. As a result, the data can be described as having different epistemologies, although both used Ordnance Survey line data to define the landscape objects which were allocated to land cover/land use classes, and different ontologies arising from the different ways that the landscape features are conceived: the Stamp data was an exclusively land use (utilization) survey, and the $\mathrm{CEH}$ Land Cover Map mixes the concepts of land use and land cover, including the land use class of urban and built-up. However, urban and suburban land use classes are some of the most reliably identified land uses, whether by field survey or from remotely sensed data, and a high degree of consistency would be expected between what is considered to be 'urban' in 2007 and in the 1930s. Additionally, any local differences in resolution and scale were minimized by aggregating the land use data over a $10-\mathrm{km}$ grid.

Second, the proportions of urban land use change were summarized over the $10-\mathrm{km}$ grid attached to each observation of first flowering. This is to assume that land use change measured in this way is of an appropriate granularity for observations of phenological timings, i.e. that a $10 \mathrm{~km} \times 10 \mathrm{~km}$ grid cell adequately captures the external factors associated with urban land use that may influence phenophase.

Third, the Julian day was corrected for elevation rather than just including elevation as an additional term in the regression analyses. The aim of this study was not to assess the impact of elevation on first flowering rather it was to evaluate the impacts of urban changes on phenophase. However, we note the recommendations of Jochner et al. (2012) of the need for long-term studies on urban phenology to consider urbanization and altitudinal effects simultaneously.

Fourth, the analysis could have applied paired models to compare rural and urban regions. However, any definition of rurality using the $10-\mathrm{km}$ grid cells would be arbitrary other than for values of 0 and $100 \%$ urban and it would be impossible to know whether the location of any observation was in a rural or urban context at that time. Rather, the urban land use proportions summarized over the $10-\mathrm{km}$ grid cells could be considered as 1 - rural land use proportions and in this way this analysis has supported the recommendations of Jochner et al. (2012) to 'go beyond a plain urban-rural comparison by taking the degree of urbanization into account'.

Fifth, while the phenophase data were recorded continuously, the urban land use change between 1934 and 2007 attached to each observation was scaled to the year of observation. This was done linearly, imposing an assumption that land use change occurred continuously at the same annual rate during this period. This is plainly not the case and the models could be improved by re-scaling observed land use changes between 1934 and 2007 using temporally distributed models of urban change.

Finally, the kernel bandwidth applied in the geographically weighted analyses can be specified as a fixed distance or to include a proportion of the data points. In this analysis, the kernel was specified to include $5 \%$ of the data in each local regression. Determining the number of data points to include has to balance working with a dataset that is too small to calibrate the model reliably against one that is too big and averages out any local effects. In this study, the median and mean values of the GWR (summarized in Tables 2 and 5) are very similar to the regression coefficient estimates (in Tables 1 and 3, respectively) indicating a bandwidth of $5 \%$ to be appropriate. Further details on bandwidth selection and the use of automated methods to chose a bandwidth that minimize the cross-validation prediction error can be found in the study of Fotheringham et al. (2002).

\section{Conclusions}

This research considered changes in early year phenophase (first flowering) amongst three tree species over time and against urban land use changes. It analysed long runs of volunteer observations of the timing of first flowering between 1934 and 2007 and linked changes in phenophase timings to changes in urban land use over the same period, thereby investigating the possible effects of UHIs. The results showed that first flowering dates are getting significantly earlier at rates varying from 0.28 to 0.13 days per year. A geographically weighted analysis of the rates of change showed that, locally, there is considerable spatial variation in these rates within and between species. Increases in urban land use were also found to be significant predictors of phenophase change with the coefficients suggesting rates of between 1.20 and 0.57 days earlier per $10 \%$ increase in urban land use depending on the species. Again, these global change coefficients rates were shown to vary considerably when the data were analysed using a geographically weighted model. However, the patterns of spatial variation were not uniquely associated with general patterns of urbanization. This suggests that (1) the impacts of climate changes vary spatially, (2) the effects urban land use changes on phenology vary spatially and (3) the impacts of urban expansion, such as UHI effects, may not be uniform. However, this research has illustrated the advantages of applying spatially explicit analyses for quantifying the local impacts of climate changes impacts and their associated feedbacks. 


\section{Acknowledgements}

The authors would like to acknowledge the support from a number of organizations and nameless individuals. The Woodland Trust for access to the UK Phenology Network data and the various groups and volunteers who have observed and recorded so many different natural events; the many schoolchildren and volunteers who mapped land use under the various county Land Utilization Surveys overseen by Sir Dudley Stamp in the 1930s; the Environment Agency for creating and providing the digital version of the Stamp data and the Centre for Ecology and Hydrology for the Land Cover Map 2007 data, available from the Countryside Survey website.

\section{References}

Appleton D, French J, Vanderpump M. 1996. Ignoring a covariate: an example of Simpson's paradox. Am. Stat. 50: 340-341.

Ashley WS, Bentley ML, Stallins JA. 2012. Urban-induced thunderstorm modification in the southeast United States. Clim. Change $\mathbf{1 1 3}$ 481-498.

Askeyev OV, Sparks TH, Askeyev IV, Tishin DV, Tryjanowski P. 2010. East versus West: contrasts in phenological patterns? Glob. Ecol. Biogeogr. 19: 783-793.

Bornstein RD. 1968. Observations of the urban heat island effect in New York City. J. Appl. Meteorol. 7: 575-582.

Brunsdon CF, Fotheringham AS, Charlton M. 1996. Geographically weighted regression - a method for exploring spatial non-stationarity. Geogr. Anal. 28: 281-298.

Chmielewski FM, Rötzer T. 2001. Response of tree phenology to climate change across Europe. Agric Forest Meteorol. 108: 101-112.

Chuine I, Morin X, Bugmann H. 2010. Warming, photoperiods, and tree phenology. Science 329(5989): 277-278.

Cochrane MA, Barber CP. 2009. Climate change, human land use and future fires in the Amazon. Glob. Change Biol. 15: 601-612.

Dirmeyer P, Niyogi D, De NobletDucoudre N, Dickinson RE, Snyder PK. 2010. Editorial: impacts of land use change on climate. Int. J. Climatol. 30: 1905-1907.

Feddema JJ, Oleson KW, Bonan GB, Mearns LO, Buja LE, Meehl GA, Washington WM. 2005. The importance of land-cover change in simulating future climates. Science 310: 1674-1678.

Foley JA, DeFries R, Asner GP, Barford C, Bonan G, Carpenter SR, Chapin FS III, Coe MT, Daily GC, Gibbs HK, Helkowski JH, Holloway T, Howard EA, Kucharik CJ, Monfreda C, Patz JA, Prentice IC, Ramankutty N, Snyder PK. 2005. Global consequences of land use. Science 309: 570-574.

Fotheringham AS, Brunsdon C, Charlton ME. 2002. Geographically Weighted Regression: The Analysis of Spatially Varying Relationships. Wiley: Chichester, UK.

Hoffmann P, Krueger O, Schlünzen KH. 2012. A statistical model for the urban heat island and its application to a climate change scenario. Int. J. Climatol. 32: 1238-1248.

Jochner SC, Sparks TH, Estrella N, Menzel A. 2012. The influence of altitude and urbanisation on trends and mean dates in phenology (1980-2009). Int. J. Biometeorol. 56: 387-394.

Jochner S, Alves-Eigenheer M, Menzel A, Morellato LPC. 2013. Using phenology to assess urban heat islands in tropical and temperate regions. Int. J. Climatol. 33(15): 3141-3151.

Korner C, Basler D. 2010. Response--warming, photoperiods, and tree phenology. Science 329: 278.

Landsberg HE. 1981. The Urban Climate. Academic Press: New York, NY.

Malhi Y, Roberts JT, Betts RA, Killeen TJ, Li W, Nobre CA. 2008.
Climate change, deforestation, and the fate of the Amazon. Science 319(5860): 169-172.

Menzel A, Sparks TH, Estrella N, Koch E, Aasa A, Ahas R, Zust ANA. 2006. European phenological response to climate change matches the warming pattern. Glob. Change Biol. 12: 1969-1976.

Morton D, Rowland C, Wood C, Meek L, Marston C, Smith G, Wadsworth R, Simpson I. 2011. Final Report for LCM2007-the new UK land cover map. Countryside Survey Technical Report No. 11/07. Retrieved March 29, 2014. http://nora.nerc.ac.uk/14854/1/LCM2007_ Final_Report_-_vCS_Web.pdf.

Oke TR. 1987. Boundary Layer Climates. Routledge: London.

Peñuelas J, Filella I. 2009. Phenology feedbacks on climate change. Science 324(5929): 887-888.

Pitman JA, Arneth A, Ganzeveld L. 2012. Review regionalizing global climate models. Int. J. Climatol. 32: 321-337.

Pope KS, Dose V, Da Silva D, Brown PH, Leslie CA, DeJong TM. 2013. Detecting nonlinear response of spring phenology to climate change by Bayesian analysis. Glob. Change Biol. 19: 1518-1525.

Poulter B, Aragão L, Heyder U, Gumpenberger M, Heinke J, Langerwisch F, Rammig A, Thonicke K, Cramer W. 2010. Net biome production of the Amazon Basin in the 21st century. Glob. Change Biol. 16: $2062-2075$.

Roetzer T, Wittenzeller M, Haeckel H, Nekovar J. 2000. Phenology in central Europe - differences and trends of spring phenophases in urban and rural areas. Int. J. Biometeorol. 44: 60-66.

Schleip C, Sparks TH, Estrella N, Menzel A. 2009. Spatial variation in onset dates and trends in phenology across Europe. Clim. Res. 39: 249-260.

Shepherd JM. 2005. A review of current investigations of urban-induced rainfall and recommendations for the future. Earth Interact. 9(12): $1-27$.

Shepherd JM, Burian SJ. 2003. Detection of urban-induced rainfall anomalies in a major coastal city. Earth Interact. 7(4): 1-17.

Simpson E. 1951. The interpretation of interaction in contingency tables. J. R. Stat. Soc. Ser. B 13: 238-241.

Smith C, Levermore G. 2008. Designing urban spaces and buildings to improve sustainability and quality of life in a warmer world. Energy Policy 36: 4558-4562.

Soares-Filho B, Nepstad DC, Curran L, Cerqueira G, Garcia RA, Ramos CA, Voll E, McDonald A, Lefebvre P, Schlesinger P. 2006. Modelling Amazon conservation. Nature 440: 520-523.

Stamp LD. 1934. Land utilization survey of Britain. Geogr. Rev. 24: 646-650.

Stöckli R, Rutishauser T, Baker I, Liniger MA, Denning AS. 2011. A global reanalysis of vegetation phenology. J. Geophys. Res. 116: g03020.

Strengers BJ, Müller C, Schaeffer M, Haarsma RJ, Severijns C, Gerten D, Schaphoff S, van den Houdt R, Oostenrijk R. 2010. Assessing 20th century climate-vegetation feedbacks of landuse change and natural vegetation dynamics in a fully coupled vegetation-climate model. Int. J. Climatol. 30(13): 2055-2065.

United Nations. 2005. Department of Economic and Social Affairs, Population Division. World urbanisation prospects: the 2005 revision. Working Paper No. ESA/P/WP/200. http://www.un.org/esa/po pulation/publications/WUP2005/2005WUPHighlights_Final_Report. pdf.

Visser ME, Both C. 2005. Shifts in phenology due to global climate change: the need for a yardstick. Proc. R. Soc. B 272: 2561-2569.

Walther GR. 2003. Plants in a warmer world. Perspect. Plant Ecol. Evol. Syst. 6: 169-185.

Walther GR, Post E, Convey P, Menzel A, Parmesan C, Beebee TJC, Fromentin J-M, Hoegh-Guldberg O, Bairlein F. 2002. Ecological responses to recent climate change. Nature 416: 389-395.

Wilby RL. 2003. Past and projected trends in London's urban heat island. Weather 58: 251-260.

Yu H, Luedeling E, Xu J. 2010. Winter and spring warming result in delayed spring phenology on the Tibetan Plateau. Proc. Natl. Acad. Sci. U.S.A. 107(51): 22151-22156.

Zhang X, Friedl MA, Schaaf CB, Strahler AH, Schneider A. 2004. The footprint of urban climates on vegetation phenology. Geophys. Res. Lett. 31(12): L12209. 